\title{
Endometrial Polyp
}

National Cancer Institute

\section{Source}

National Cancer Institute. Endometrial Polyp. NCI Thesaurus. Code C6433.

A benign nodular lesion protruding above the surface of the endometrium. It is composed of a fibrous stroma that contains thick-walled blood vessels and dilated endometrial glands. Polypectomy is the treatment of choice. Only few cases with recurrence have been reported. 